\title{
ICT in Education: Open Source Software and its Impact on Teachers and Students
}

\author{
Soma Bandyopadhyay \\ MCKV Institute of Engineering, \\ Liluah, Howrah
}

\author{
S. S. Thakur \\ MCKV Institute of Engineering, \\ Liluah, Howrah
}

\begin{abstract}
ICT in education plays a major role as teaching-learning process is concerned. There is an urgent need to improve the use of ICT education so that our schools and learners get the benefits of advances done in information technology. We have observed a stiff rise in usage of Social Media such as Twitter, Facebook and the ubiquitous nature of mobile applications. Students studying in higher classes are already familiar with social media and their dependency on the usage of these technologies have been increased many fold. Hence, we have to prepare our students so that they can face the challenges of IT using open source technologies which will act as a separate subject rather than a supporting platform for all subjects.
\end{abstract}

\section{General Terms}

Internet and Distributed Computer Systems.

\section{Keywords}

Information and Communication Technology - ICT, Open Source Software - OSS and free software, National Program on Technology Enhanced Learning - NPTEL, Resource Centre etc.

\section{INTRODUCTION}

ICT acts as an object which refers to learning using Information and Communication Technology. What is being learned depends on the type of education and the level of the students. Education prepares students for the use of ICT in education, future occupation and social life. ICT $[1,2]$ acts as an 'assisting tool' while making assignments, collecting data and documentation and for communicating and conducting research. ICT is a medium for teaching and learning and refers as a tool for teaching and learning itself, the medium through which teachers can teach and learners can learn. It appears in many different forms, such as drill and practice exercises, in simulations and educational networks. ICT [3, 4] acts as a tool for organization and management in schools. ICT- skills are partly necessary for using ICT in education.

A number of schools have been experimenting with using Twitter in the classroom in order to engage the students in a familiar environment and so embrace the development of IT [5] in education. Many of the reported benefits include increased engagement, increased participation and concise writing. However, there are downsides to using Twitter in the classroom as part of using IT in Education and they include security, ability to capture the learning, working with large numbers of students and the inability to handle a wide range of digital media such as video, documents, spreadsheets, presentations etc. There are two main aspects of IT in education:

\subsection{Enabled personalized learning:}

Technology can offer a personalized learning environment that is tailored to students' individual differences such as progression level, pace, interests, learning style, and background. It also provides the support and challenge required to keep students engaged and motivated and empowers them to reach their potential.

\subsection{Greater Community involvement:}

Technology can help parents' and community members' involvement in student learning by using methods such as school websites, email, blogs, text-messaging, etc. to keep interested persons aware and engaged in their local education system.

\section{OPEN SOURCE SOFTWARE}

In our education system the tools which are mostly used includes books, teachers, infrastructure and partially Opensource software (OSS) [6, 7]. As open source software is concerned it is playing a vital role in education in recent times. OSS [8] is a computer software available and licensed with the copyright holder which provides the right to study, change and distribute the same at free of cost to anyone and for any purpose. Open-source software is developed in a collaborative manner by people or user groups. A report by the Standish Group (2008) states that adoption of open-source software models has resulted in savings to consumers of about $\$ 60$ billion per year.

The free software movement was launched in the year 1983 and that was followed by a group of individuals who advocated that the term free software should be replaced by open-source software (OSS) in 1998 which is more comfortable and less ambiguous for the corporate world. It has been observed that Software developers have shown keen interest to publish their work with an open-source license, so that anybody may contribute to the developed software can understand its internal functioning. With open-source software, anyone is free to do certain modifications on it and can port it to new operating systems, processor architecture, may share it with others and if required can market it. Scholars Casson and Ryan [9] pointed out many policy-based reasons in adoption of open source particularly the heightened value proposition from open source compared to proprietary formats in following categories:

- Security

- Affordability

- Transparency

- Perpetuity

- Inter-operability

- $\quad$ Flexibility 
Casson and Ryan argue that mostly governments have an inherent responsibility and duty to taxpayers and it includes careful analysis of certain factors when someone implements open-source software or decide to purchase proprietary software. Most popular example is the GNU General Public License (GPL), which allows the developers for free distribution of the software putting certain constraints that any further new development and applications needs to be put under the same license. Open-source distribution presents a unique way to make the source code of a product accessible by public and licenses allow the developer to do the fine tuning for the same. The open source came out of a strategy session held on April 7, 1998 in Palo Alto in reaction to announcement made in January1998 which was named as a source code release for Netscape Navigator (as Mozilla). They used this opportunity before the release of Navigator's source code which clarifies the ambiguity of the word "free" in English.

The Open Source Initiative (OSI) was formed in February 1998 by Eric S. Raymond and Bruce Perens [10]. Case histories of last 20 years were taken as an evidence for discussion of closed software development versus open software development and the same has been provided by the Internet developer community. The OSI thought that the use of the label "open source," as suggested by Peterson of the Foresight Institute at the strategy session may eliminate ambiguity in particular for individuals who perceive "free software" as an anti-commercial product but that attempt was impractical by trademark standards. Raymond discovered from the Press Release, that Netscape released its Navigator source code as an open source which had quite favorable results.

In our study, we propose to use OSS $[6,7,8]$ as an important tool in education for the benefit of students in general \& society in particular. Proposed Work and its methodology is explained in Section 3 and 4 respectively. Section 5 and 6 explains qualities of Effective teachers and research questions followed by advantages, disadvantages and concluding remarks.

\section{PROPOSED WORK}

A work flow diagram may be enunciated as follows for the actions needed as shown in Figure 1. In the following work flow diagram, IIT, Mumbai is the academic centre and it proposes the use of open source software (Spoken-Tutorial) for learning of different OSS mentioned above. We propose, in the initial stage, training/learning will be given to the faculty/engineering students as per their areas of interest. They can get certificate after qualifying the examination. The job of the resource centre is to identify the schools and colleges in their locality and after convincing them, prepare a schedule as per the requirement of the students for learning through OSS. The certified faculty and engineering students may prepare presentations for the open source software which is unavailable in the academic centre. They can be considered as add-on courses and give it back to the academic centre so the same can be used around geographical locations without any binding.

Certified faculty and engineering students will visit the schools and teach the students initially by using blackboard/chalk pattern or ppt. Then the tutorials of the video lectures will be provided by the students for selflearning [11].

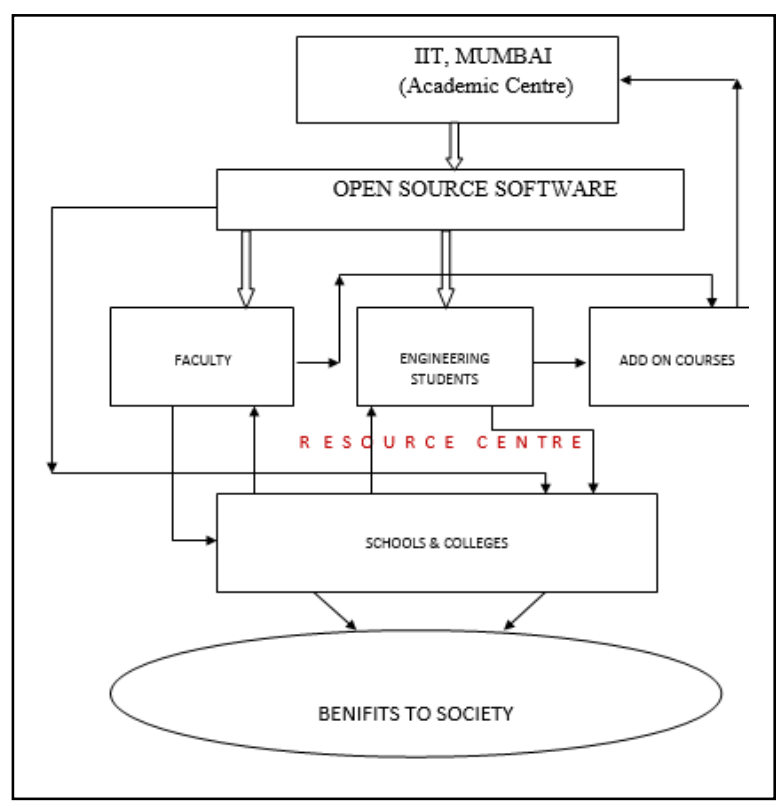

Fig 1: Work Flow Diagram depicting Proposed Work

Once they self-learned, they can visit the resource centre and interact with the faculty and the certified engineering students of the centre and clear their doubts, if any. This type of teaching is a blend of teacher teaching [11] a class along with self-learning of video lectures by the students which enables them to grasp the concept in a more efficient manner without any financial involvement. The different layers of active learning environment is shown in Figure 2. In this manner, the overall teaching-learning process using OSS will be a big benefit to the society.

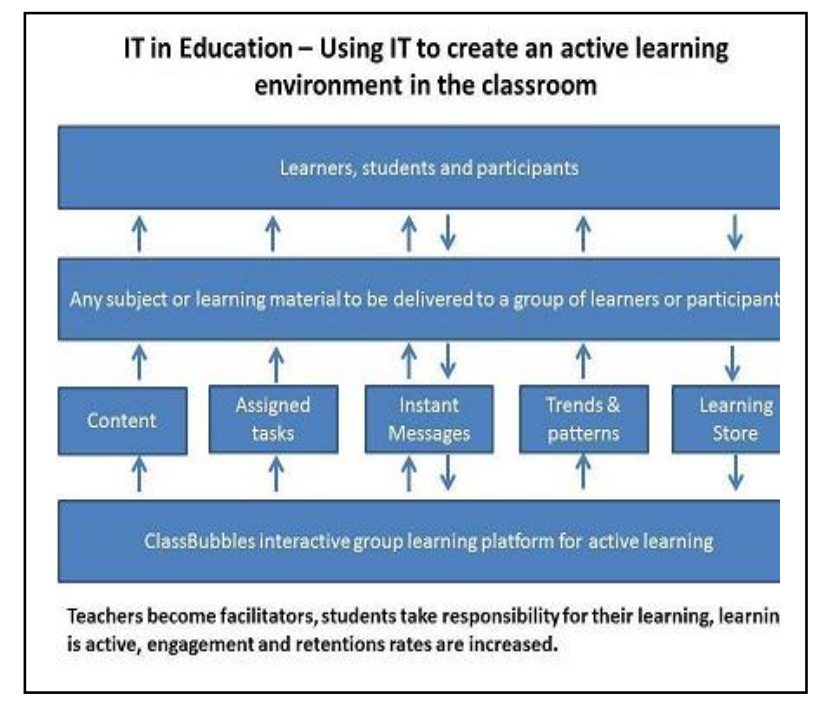

Fig2: Different layers of Active Learning Environment

\section{METHODOLOGY}

The principles of open source have been adapted for many forms of user-generated content and technology, including open-source software, Wikipedia, and openaccess publishing etc. This "culture" takes the view that these principles apply more generally to facilitate concurrent input of different approaches and priorities in contrast with centralized models ofdevelopment which are typically used in commercial companies. So suggestions of using open source software to create an active learning environment in the class room will be beneficial. 
Some of the available software tools/methods can be used for the purpose of self-learning such as:

- Email

- Facebook

- Twitter

- LinkedIn

- Google

- $\quad$ NPTEL: Video \& Text lectures

NPTEL is the open source learning, video based course developed by major IITs (Delhi, Mumbai, Kanpur, Kharagpur and Madras) for engineering education. This project was funded by Ministry of HRD, GOI. The same has been telecast throughout the country by a channel "Gayandarshan" and "Eklabya" channel. It is having following features:

- Recorded lectures for engineering subjects with a content of roughly forty hours.

- It is a dynamic experience for the students.

- It is interactive-Students can ask questions and get solutions.

- It's reach to global village virtually.

- It is learner centric and retains contextuality.

- The storage and retrieval mechanism are easy

Any education institute, if requires this NPTEL lectures, may send a representative with a request letter to IIT, Madras along with two terabyte hard disc so that it can be copied and used in their institute.

NPTEL has signed an agreement with Google for getting the dynamic response of their video based course for having more information. For this purpose the site is http://hptel.iitm.ac.in. Figure 3 shows uses of open source software at different locations. One of the examples of these is spoken tutorial.

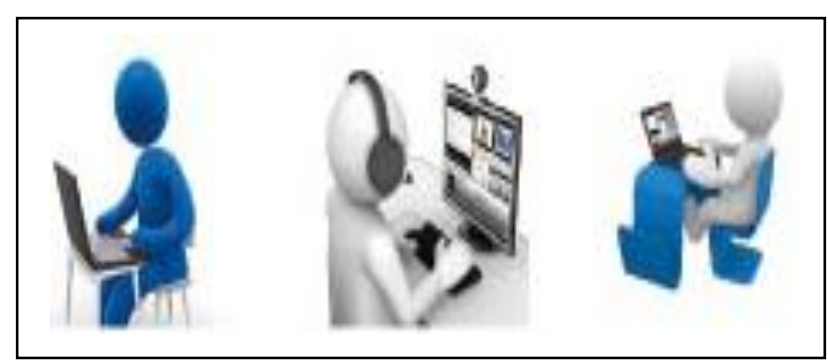

Fig 3: Uses of OSS

Spoken Tutorial: An initiative of national Mission on Education through ICT Government of India to promote IT Literacy through Open Source Software.

There are two types of centers namely Academic Centre and Resource Centres. The job of academic centre is to provide open source software namely:

Basic IT Skills in different languages like English, Bengali, Gujrati, Hindi, Marathi, and Tamil etc.

- Latex

- Java

- Linux

- Netbeans

- Php - Mysql

- Python

- Scilab etc.

At this mode of learning, participants and students have to download all these open source software mentioned above with the permission of IIT, Mumbai. They called this process as a workshop and one has to register for the same at free of cost. Once the participants learn from this video lectures, they may appear for an Online Assessment Test and Certificates are given to the participants based on the performance which may help the students to get employment in the relevant fields.

One can become a resource centre after signing an MOU with spoken tutorial-IIT, Mumbai. The initial job of resource centre is to identify four schools and two engineering institutions in their periphery who are interested in learning through open source software for the benefit of the students.

The other features available with Spoken-Tutorial are to collaborate with IIT, Mumbai for the following purpose:

Institute/individual can become a Workshop Ambassador/ Contributor.

One can suggest a Topic/an example.

[Address: Project Incharge "Talk to a Teacher"

TCS Lab, Behind CAD Centre, Near Estate Office

Department of Chemical Engineering, IIT Mumbai, Powai,

Mumbai - 400076Spoken-tutorial.org]

A case study of OSS in West Bengal in which 69 Institutes participated and the results are as follows:

Total No of Workshops held - 106

Total no of participants attended -3301

The above data is from 18th November, 2011

\section{QUALITIES OF EFFECTIVE TEACHERS}

It is well known that these highly effective teachers can have an enriching effect on the daily lives of children and their lifelong educational and career aspirations. These effective teachers also have a direct influence in enhancing students' learning. Years of research on teacher quality support the fact that effective teachers $[12,13]$ not only make students feel good about school and learning, but also their work actually results in increased student achievement. Studies have substantiated that a whole range of personal and professional qualities are associated with higher levels of student achievement. For example, it has been observed that verbal ability, content knowledge, pedagogical knowledge, certification status, ability to use a range of teaching strategies skillfully and enthusiasm for the subject characterize more successful teachers. The following are some of the key qualities of effective teachers:

- Have formal teacher preparation training.

- Hold certification of some kind (standard, alternative, or provisional) and are certified within their fields.

- Have taught for at least three years.

- $\quad$ Are caring, fair, and respectful.

- Hold high expectations for themselves and their students.

- Dedicate extra time to instructional preparation and reflection.

- Maximize instructional time via effective classroom management and organization. 
- Enhance instruction by varying instructional strategies, activities, and assignments.

- Present content to students [14 ] in a meaningful way that fosters understanding.

- Monitor students' learning by utilizing pre- and postassessments, providing timely and informative feedback, and re-teaching material to students who did not achieve mastery.

- Demonstrate effectiveness with the full range of student abilities in their classrooms, regardless of the academic diversity of the students.

\subsection{Measurement of student learning}

One additional concern about the use of student learning assessments in the teacher $[15,16]$ evaluation process is the way in which learning is assessed. The traditional use of grades or standardized achievement scores is certainly suspect for a variety of reasons, including the following:

- Accuracy of grading procedures.

- Alignment of achievement tests with the curriculum.

- Diagnostic value of either approach for instructional improvement.

- Single-point-in-time nature of these indicators.

In the absence of meaningful pre-test data, grades or achievement test scores at the end of the year are hardly valid measures of a teacher's influence during a given year indeed, they reflect the cumulative effects of what students have learned at home and school over preceding years. A much more accurate measure of what a student has learned would be reflected by an assessment that is curriculum-aligned and administered both at the beginning and end of the year. When such learning gains are averaged over a whole class of students, we have a general indication of the magnitude of learning that took place with that group of children.

\subsection{Meaningful feedback for instructional improvement}

Feedback in the form of assessment data offers a valuable tool for supervision [17]. As Barbara Howard and Wendy McColskey [18] mentioned that evaluation leads to professional growth, which requires teachers to look honestly at their own strengths and weakness. The purpose of Selfassessment is limited due to lack of objectivity. Similarly, feedback from colleagues based on a few classroom visits is equally limited because it provides a narrow sampling of behavior. Assessment data of student learning over a period can provide enough feedback on students' overall understanding of the topic. In addition to this, broader sampling of the teacher's impact on students permits identifying specific patterns in learning of content and skills that were taught.

The evidence obtained from schools shows that there has been increasing pattern of performance in the students' achievements in particular those belongs to high poverty and minority populations. Data analysis has been used as a means of monitoring success and ensuring accountability for identifying goals of entire education system. Two-thirds of the teachers' survey data in schools found that to understand their students' skills gaps it requires regular monitoring for achieving better results. Instructional responsiveness to student assessments is a powerful tool for increased student achievement.

\section{RESEARCH QUESTIONS}

The following questions are posed in our study:

- What are the consequences on the usage of ICT in occupational practice on secondary education?

- What are the steps involved to bridge the gap between new educational insights and the use of ICT in educational practice?

- What are the consequences of ICT on curriculum development and its usage on job scenario for professionals?

Looking at the research results, it seems better not to argue for specific ICT-skills for teachers as they can easily adjust by the implementation of ICT in education. How to implement ICT in education mainly seems to be a design-problem which has less relevance as the teaching learning process is concerned. Teachers require skills and competence for solving specific problem which are defined within the concept of core problems. Core problems can be defined as the central problems and dilemmas in professional practice as regularly encountered by professionals. Core problems are an interesting basis for education, as they define the professional core and select the content. The professional is an individual who is positioned in the center as a center head and responsible for monitoring all the ICT based features and functionalities as education is involved.

\section{ADVANTAGES AND DISADVANTAGES OF OSS AND COMPARISON WITH FREE SOFTWARE}

\subsection{Advantages}

The top four reasons provided by Open Source Business Conference survey why individuals or organizations choose open source software are:

- Lower cost

- Better quality

- No vendor involvement

- Security

Since reputed companies do not rely heavily on software sales, proprietary software has become less of a necessity. Things like open source content management system (CMS) deployments are becoming more common. In 2009, the US White House switched its CMS system from a proprietary system to Drupal open source CMS. Further, companies like Novell who sold software in an old-fashioned way continually debate the benefits of switching to open source availability, have already switched part of the product business offerings to open source code. In this manner, open source software provides solutions to unique or specific problems. It is reported that $98 \%$ of enterprise-level companies use open source software offerings in some or other capacity.

With this market shift, critical systems are beginning to rely on open source offerings which allow greater funding and helps in hunting security bugs. If anyone argues that open source software does not have flaws which are an incorrect version. One of the greatest barriers in wide acceptance of open-source software is due to the lack of technical and general support. An 
open-source company tries to overcome this situation by offering support under a different product name. For instance Acquia provides enterprise-level support for its open-source alternative, Drupal. Many argue that open source software is safer because any person can view, edit, and can change code. But closed-source software suggests that individuals that aren't paid to right code are not paid any incentive for doing monotonous type of work.

\subsection{Disadvantages}

There are commonly recognized barriers to the adoption of open-source software by enterprises. The reasons beyond this barriers includes that open-source licenses are viral, formal support and training is inadequate, frequency of change is not known and absence of long-term roadmap. The majority of these barriers are risk-related. Whereas on the other side for all proprietary projects disclose exact future plans,and many seriousOSS projects (especially operating systems) actually make money for providing support and documentation.

\subsection{Comparison with Free Software}

The main difference is that by choosing one term over the other (i.e. either "open source" or "free software") one lets others know about what one's goals are. As Richard Stallman puts it, "Open source is a development methodology free software is a social movement."

Critics have said that the term "open source" fosters an ambiguity of a different kind such that it confuses the mere availability of the source with the freedom to use, modify, and redistribute it. Developers have used the alternative terms Free/open source Software (FOSS), or Free/Libre/open source Software (FLOSS), consequently, to describe open source software which is also free software.

\section{CONCLUSION}

Open source software is used as an important tool for educating students as well as other participants at no cost. Seminars, symposiums, workshops are needed for better understanding the usefulness of open source learning which is useful to reach the students and communities who are not aware of this resource. One should be careful regarding the selection of different sources of open source software.

Across the United States, school accountability is a theme now commonly heard among state government officials and local community members. Parents, policymakers, and educators have examined their public schools and demanded for their improvement. Schools are taking lot of efforts in a variety of ways out of which the most important focus is on teacher's standard and improvement in student performance. These goals were discussed by the powerful opening salvo in the 1996 report, What Matters Most: Teaching for America's Future, by the National Commission on Teaching and America's Future. It was proposed on an audacious goal by the year 2006, America will provide all students in the country with what should be their educational birthright: access to competent, caring, and qualified teachers.

The commission followed this statement with some major recommendations:

- Get serious about the standards for both students and teachers.

- If students are to achieve high standards, we can expect no less from their teachers and other educators.

- If teachers make a difference in students' learning, and if we are to have competent and caring teachers, shouldn't we relate teachers' work to the students work?

- Finally Teacher's effectiveness can be measured by student's achievement.

\section{ACKNOWLEDGMENTS}

The authors are thankful to Dr. Parasar Bandyopadhyay, Director, MCKVIE and Dr. Asok Kumar, Principal, MCKVIE for providing us the Computer laboratories and other infrastructure to do the proposed work.

\section{REFERENCES}

[1] Murray, James (2011-12-18). "Cloud network architecture and ICT - Modern Network Architecture". IT Knowledge Exchange. TechTarget. Retrieved 2013-08-18.

[2] "Information and Communication Technology from". FOLDOC. 2008-09-19.

[3] Zuppo, Colrain M. "Defining ICT in a Boundary less World: The Development of a Working Hierarchy" (PDF). International Journal of Managing Information Technology (IJMIT). p. 19. Retrieved 201602-13.

[4] "ICT in Education". From Wikipedia, the free encyclopedia, Unesco. Unesco. Retrieved 10 March 2016.

[5] "IT Costs - The Costs, Growth And Financial Risk Of Software Assets". OMT-CO Operations Management Technology Consulting GmbH. Retrieved 26 June 2011.

[6] Verts, William T. (2008-01-13). "Open source software". World Book Online Reference Center. Archived from the original on January 1, 2011.

[7] Rothwell, Richard (2008-08-05). "Creating wealth with free software". Free Software Magazine. Retrieved 200809-08.

[8] "Standish Newsroom - Open Source" (Press release). Boston. 2008-04-16. Retrieved2008-09-08.

[9] Tony Casson, Patrick S. Ryan, "Open Standards, Open Source Adoption in the Public Sector, and Their Relationship to Microsoft's Market Dominance by:: SSRN". Papers.ssrn.com. Retrieved 2015-03-30.

[10] Eric S. Raymond and Bruce Perens , "Open Source Initiative", from Wikipedia - the free encyclopedia, 1998

[11] Darling - Hammond, L. "Teacher quality and student achievement: A review of state policy evidence. Education Policy Analysis Archives," Volume 8 Number 1 January 1, 2000, ISSN 1068-2341

[12] Mendro, R. L. (1998). "Student achievement and school and teacher accountability. Journal of Personnel Evaluation in Education, 12, 257-267, p. 262.

[13] "ITU releases annual global ICT data and ICT Development Index country rankings". www.itu.int Retrieved 2015-09-01.

[14] Marzano, R. J., Pickering, D. J., \& Pollock, J. E. (2001). "Classroom instruction that works: Researchbased strategies for increasing student achievement. Alexandria, VA: Association for Supervision and Curriculum Development." 
[15] Wright, S. P., Horn, S. P., \& Sanders, W. L. (1997). "Teacher and classroom context effects on student achievement: Implications for teacher evaluation". Journal of Personnel Evaluation in Education, 11, 57-67, p. 63.

[16] Schalock, H. D. (1998). "Student progress in learning: Teacher responsibility, accountability and reality. Journal of Personnel Evaluation in Education," 12(3), 237-246.
[17] Stronge, J. H., \& Tucker, P. D. (2003). "Handbook on teacher evaluation: Assessing and improving performance. Larchmont, NY: Eye on Education.”

[18] Howard, B. B., \& McColskey, W. H. (2001). "Evaluating experienced teachers. Educational Leadership," 58(5), 48-51, p. 49. 